\title{
Foreign Language Assessment: Instructional Considerations for Students with Specific Learning Disabilities
}

\author{
Joshua B. L. Tolbert \\ School of Education, Indiana University East, Richmond, IN, U.S.A.
}

\begin{abstract}
Students with specific learning disabilities (SLDs) continue to be more likely to experience anxiety about learning a foreign language, and possibly less likely to enroll in foreign language courses at all. As schools become more inclusive and more aware of diverse learning needs, it is important to be cognizant of how the individual needs of students with SLDs may relate to classroom instruction and assessment practices. What follows is a discussion of assessment practices, with an emphasis on diagnostic and formative assessment in the context of teaching students with SLDs. Given the prevalence of mobile phones and other devices in contemporary classrooms, a strong emphasis on the role of online polling resources plays a prominent role in this discussion. Specific examples of instructional activities which align with assessments are also provided, as part of a selective literature review intended to connect larger topics in language instruction to the typical needs of students with specific learning disabilities. The perspective of the discussion pertains primarily to students with SLDs in the United States, where the vast majority of foreign language instruction occurs in the middle and secondary grades.
\end{abstract}

Index Terms - world languages, specific learning disabilities, diagnostic assessment, formative assessment

\section{INTRODUCTION}

In order to truly promote success for students with specific learning disabilities in learning new languages, there must be due consideration of both effective practices for instruction and assessment. The concern that students identified with specific learning disabilities (SLDs) experience heightened anxiety or difficulty in learning foreign languages has been documented (Barr, 1993; Dal, 2008). Although prior research efforts have centered on multisensory instruction and strategies for learning new languages (Sparks et al., 1998; Tolbert et al., 2015), it is also vital not to overlook the role of assessment in promoting success for students with SLDs. Part of the urgency for attention to foreign language instruction and assessment for students with SLDs is that many such students are expected to complete the requirements for a high school diploma; numerous states and districts in the United States now require students to complete foreign language courses as part of that process (Education Commission of the States, 2017). Rhodes and Pufahl (2009) indicated that the majority of foreign language instruction in the United States is offered at the high school level, followed by middle and elementary schools. Further, Spanish continued to be the non-English language offered most frequently in the U.S. (Rhodes \& Pufahl, 2009), so any discussion or research of foreign language study for students with SLDs would more likely be relevant to students learning Spanish and the middle or high school grade levels.

What follows will be a discussion of methods of assessment, with emphasis on diagnostic and formative assessment, and the relevance of these approaches to students with SLDs. Since multisensory approaches have been demonstrated to be integral to the success of students with SLDs, a multisensory instructional context will be a necessary part of the following discussion of teaching and assessing. After briefly discussing diagnostic assessment, a general description of multi-sensory methods and prior research will lead to a discussion of specific, formative measures such as response cards, electronic polling, portfolios, collaborative projects, and student interviews.

\section{BASEline Data AND STUdent Profiles}

In broader educational parlance, the word "assessment" may generally connote a formal, often summative measure of performance. Special education assessment is more comprehensive, and must be understood to be an ongoing and diagnostic process (McLoughlin \& Lewis, 2008). Further, "It can be defined as the systematic process of gathering educationally relevant information to make legal and instructional decisions about the provision of special services" (McLoughlin \& Lewis, 2008, p. 4). Koretz (2008) similarly emphasized the diagnostic use of assessment, noting the importance of gathering multiple measurements and multiple types of data, and exercising sound judgment in forming conclusions. Accordingly, meaningful assessment must first provide information on the strengths and weaknesses of an individual, as well as a general impression of their performance, drawn from multiple sources. An important aspect of understanding how a student with a specific learning disability may function in the classroom is the unexpected pattern of strengths and weaknesses, which varies by individual and requires detailed diagnostic assessment (Schultz, et al., 
2012). A consequence of this unexpected pattern of strengths and weaknesses is that students with SLDs may experience little difficulty in some aspects of L1 or L2 learning (such as reading fluency), while struggling greatly in a related skill (such as reading comprehension). For this reason, ongoing assessment that uses multiple points of data is important in both the initial identification of a specific learning disability, and also in monitoring an individual student's performance in their coursework (Schultz et al., 2012).

As part of inclusion of students with learning disabilities in a foreign language classroom, Duvall (2006) recommended that teachers begin by assessing their own strengths and the procedures and organization of the classroom. Subsequently, Duvall (2006) provided an example of student profiles created for each student with special needs, with data gleaned either from documentation or direct observation of behaviors. This was supported by McLoughlin and Lewis (2008), who asserted that assessment hinges on clear definitions and measurable, observable behaviors. Although some of these guidelines are most pertinent to initial evaluations for special education services, and based in legal expectations, the practice of clearly and thoroughly determining a student's needs has wider applicability. An assessment of a student's individual needs, as well as strengths and weaknesses, can also be considered diagnostic assessment which informs decisions made about instruction, including determination of appropriate accommodations, strategies, and resources.

In devising and enacting a multi-sensory experience to help students with learning disabilities succeed in learning basic Spanish, it is helpful to understand relative weaknesses of an individual student, as well as strengths and preferences. For example, if a student displays a relative weakness in reading fluency in English, but is relatively strong in letter-word identification, then this has to be considered in providing instruction or intervention. Dennis (2009) determined that a flaw in numerous reading programs was the failure to adequately address the needs of individual students. In many cases, reading interventions were based in one dimension of reading, typically phonics (Dennis, 2009). Unsurprisingly, Dennis (2009) concluded that phonics interventions did have positive outcomes for students who really needed to improve their command of phonics, but other students were essentially left idling, with their reading needs ignored. Relative student weaknesses are important to assess in a Spanish program, as working with an additional language can be an opportunity to address these weaknesses, with the understanding that language-based learning disabilities are likely to manifest symptoms across multiple languages (Ganschow \& Schnieder, 2006; Sparks and Ganschow, 1993).

Student strengths and preferences are also important in guiding educational decisions. McLoughlin and Lewis (2008) noted the importance of using informal procedures in addition to formal ones, which may be essential to identifying relative strengths. Such strengths and preferences may be observed in informal situations, rich data can be gathered without formal measures. McLoughlin and Lewis (2008) also remarked that it is valuable to determine which conditions are preferred by students and most conducive to accomplishing tasks. Assessing expressive preferences and comfortable conditions should shape not only accommodations and strategies for individual students, but can indicate which later modes of assessment may provide meaningful data about progress (McLoughlin \& Lewis, 2008).

\section{General Multisensory Considerations}

The concept of multi-sensory instruction, specifically the engagement of one or more of the five senses in educational activities is well-established; multi-sensory methods for teaching reading or language can be traced back to at least the efforts of Orton and Gillingham in the early $20^{\text {th }}$ Century (Morin, 2017). In a multi-sensory foreign language program, students with learning disabilities have been shown to benefit from being engaged more fully, with multiple sensory inputs or expressions involved in learning tasks (Sparks et al., 1998). Logically, the same premise can be applied to assessments rooted in the curriculum; if the instruction is multi-sensory, the assessment should be, too. A given student would still need to correctly pronounce as many words as possible in the allotted time, but could use different stimuli to produce the responses. Translating from a new language to English could include several options, such as allowing the student to respond orally or in writing. Further, students could also incorporate movements which may have been paired with the word during instruction, combine oral responses with a drawing or gesture, or make a recognizable drawing. Instead of writing the word on paper, the student could have a more tactile experience, such as writing in sand, or arranging physical letters (magnetic, wood, paper) to spell the given words.

It is important to note that the techniques pioneered by Gillingham were intended to aid students with SLDs in reading and language tasks in their first language. However, the multi-sensory nature of principles developed by Orton and Gillingham, coupled with evidence that multi-sensory methods benefit students with SLDs learning new langauges (Sparks et al., 1998) could make the application of the Gillingham method to a second language a starting point for instruction and assessment. The Gillingham method used a technique called simultaneous oral spelling, in which a teacher says a spelling word, and the student repeats the word, names the individual letters while writing them, and then says the word (Gillingham \& Stillman, 1997). The oral component of this process could be combined with using one of the tangible forms of letters instead of writing, and a further option might involve spelling the words using the names of the letters in the new alphabet (especially if the language being studied uses essentially the same alphabet as English). As the examples offered in this section might indicate, a multi-sensory approach can offer a numerous possibilities for instruction and assessment, which can address the needs of the learner, and which are also influenced by research linking elaborate encoding to memory formation and retrieval (Mayer, 2002; Medina, 2008; Moreno \& Mayer, 2007). 


\section{RESPONSE CARDS AND ElECTRONIC POLLING}

One possible multisensory approach to support students with SLDs would be to supply the student with a series of cards illustrating a pre-selected list of vocabulary words, possibly in thematic groups. These cards could be arranged in a line in front of the student, for the sake of organization and access, and answers given by holding up and replacing cards. Assessment of spelling similarly offers a similar array of options, and may have the most direct ties to multisensory methods (Fernald, 1988; Gillingham \& Stillman, 1997). This method also illustrates the utility of response cards in classroom instruction, which can have a positive impact for students with SLDs.

Generally speaking, the use of response cards has been demonstrated to promote student engagement and correspondingly increase academic success and progress in L1 learning (Heward et al., 1996; Munro \& Stephenson, 2009). As with the example above, the work of Heward et al. (1996) is most relevant to elementary and middle school learners, but could have broader application to L2 learning. Response cards, particularly cards with pictorial or graphic elements, could reasonably be utilized in learning vocabulary in any new language. Response cards can also allow for more immediate corrective feedback and opportunities for teachers to identify concepts which may be challenging for students (or which may need to be covered again). Students with SLDs have been shown to experience learned helplessness to a greater extent than even other struggling students (Valas, 2001), so active participation in learning and increased frequency and quality of feedback are particularly crucial to learning goals being met. In addition to more traditional response cards, electronic polling options exist and can offer similar benefits to all students in inclusive classrooms. Two particular examples of electronic polling are Plickers and Mentimeter, both of which are proposed below as methods with applications as either diagnostic or formative assessment tools.

\section{A. Plickers}

Plickers is a free electronic polling system which allows "quick checks for understanding to know whether your students are understanding big concepts and mastering key skills" (Plickers, 2017). The principle is similar to response cards, with students using coded cards with four possible responses, with individual responses scanned by the instructor with a mobile phone. One advantage of using Plickers is that it allows for near-immediate data collection, meaning that student responses can be given prompt feedback as a seamless part of a lesson. Another advantage is that student responses can be anonymous as far as the larger class is concerned, but the instructor can assign cards to students and determine which students gave certain responses. Logistically, Plickers can also offer the benefit of not requiring a great deal of equipment or possible complications; a supply of printed cards and a mobile phone are the only tools really needed.

As diagnostic assessment, Plickers could be used effectively to identify students who may be closer to mastery, or who may need more individualized support. This information could give the instructor a basis for differentiating instruction or creating heterogeneous groups for activities. Depending on the stage in a lesson or unit of study, Plickers could also be used as formative assessment and promote similar determinations about students who may need more targeted support or more challenging tasks. For students with SLDs, using Plickers can offer the benefits of anonymous responses, active engagement, and increased opportunities for feedback or teacher interventions.

\section{B. Mentimeter}

Mentimeter is a free online polling tool which requires students to have access to a device (phone, tablet, laptop) and Internet connection, but also boasts a wider variety of question and display options than Plickers does. For example, questions can be open-ended, multiple-choice, displayed in a word cloud, or bar graph in real time. Much like Plickers, there is immediacy and anonymity of the data collection, though Mentimeter may give some added flexibility or visual variety that appeals to students.

This flexibility can be particularly valuable for diagnostic assessment, as instructors may wish to use different types of questions or obtain varying degrees of detail in diagnostic information. One example is the option to gather short, individual responses anonymously from students. As with response cards, all students have an opportunity to respond and get feedback, rather than having to depend on the instructor calling on them. This can be particularly beneficial for students with SLDs who struggle with oral expression, and can also be an effective way to incorporate the technological literacy of today's students into the classroom in a positive way.

\section{FORMATIVE ASSESSMENT OPTIONS}

\section{A. Portfolios}

Kleinert et al (2007) proposed the use of alternative forms of assessment, such as student portfolios, because, "this allows students multiple ways of demonstrating their knowledge of the language” (p. 27). Duvall (2006) similarly promoted the use of a portfolio of student work which could include video, audio, and written samples from a student. McLoughlin and Lewis (2008) asserted that portfolios could be an effective and meaningful way to record and demonstrate progress over time, and should be aligned with the specific instructional goals of individuals with learning disabilities. Importantly, portfolios may be advantageous for students who have experienced a pattern of failure and feel that successful learning is beyond their control or influence. A portfolio can be personalized, incorporates a variety of 
experiences and expressions, and results in a tangible artifact to display growth. This process can be used as both an explicit way to practice organizational skills, which often benefits students with SLDs, but also could be framed as a consistent way to reflect on progress. This growth-based perspective can take portfolios into a more formative realm, rather than having the portfolio serve as a collection of work and summative assessment.

Because anxiety and attitudinal factors can impact student performance and motivation in a foreign language (Dal, 2008; Kormos \& Safar, 2008; Levine, 1987; Scott \& Manglitz, 1997; Thurston et al., 2009), assessment opportunities which do not compare students with disabilities to their peers, or imply ranking and judgment, may be more effective.

In order to make portfolios worthwhile, they must be based in the same sort of systematic process as instruction. Guidelines for doing so were described by Salend (1998), including making the goals of the portfolio explicit, deciding on procedures to be employed, selecting an array of products relevant to the portfolio goals, regular review of portfolios, and making record of the significance of items included. Beyond serving as an individualized and authentic means of assessment for students with learning disabilities, portfolios have also been established as an appropriate means of assessing students learning a second language. Yu-Ju et al. (2005) described a Taiwanese study in which electronic portfolios served as an effective way to assess not only the progress of learners, but also the success of the language program. Because the portfolios were tied closely to the language instruction, the portfolios became both a teaching tool and an assessment tool (Yu-Ju et al., 2005). As addressed by Nikolov and Djigunovic (2006), language portfolios have sometimes been embraced outside the United States as an innovative indicator of proficiency in foreign language.

\section{B. Cooperative Projects and Products}

Like student portfolios, cooperative projects and products can offer alternative avenues for students to demonstrate content knowledge and growth. Cooperative projects and products may offer flexibility in student involvement and mode of presentation. Duvall (2006), for instance, recommended a class project as an alternative foreign language assessment, such as putting on a play. Such a project could promote the inclusion of students with disabilities in meaningful ways, while still allowing flexibility for varying levels of confidence or skill. Another example of a fullclass project in foreign language study was described by Pellet (2012), in which a French class collaborated to create a wiki. Pellet (2012) concluded that the active, constructivist approach allowed for meaningful learning, while also benefitting from continuous instructor feedback. Similar projects might also allow individuals or small groups of students with learning disabilities to participate in inclusive classrooms and address social skills, while simultaneously offering another means of assessment.

\section{Student Interviews}

Along with formative assessment practices like journals, projects, and portfolios, Ketabi and Ketabi (2014) noted that student interviews have gained traction as a form of assessment for students learning new languages. Since traditional written tests can be especially problematic for students with SLDs, a form of assessment that allows for oral expression and direct one-on-one assessment may reduce anxiety and provide more precise information about a particular student's progress. Having tests presented orally, instead of in writing, is a common and accepted accommodation for students with learning disabilities, and interviews are also accepted as a means of assessing student needs and progress. McLoughlin and Lewis (2008) stated that interviews can be employed as an alternative form of assessment when literacy creates obstacles or to set a student at ease, though it is important to note that the accuracy of the information relies upon the memory and perceptions of the student. Nevertheless, benefits of interviews are that, "an interviewer can guide the informant through the questioning, keep him or her on track, and probe for additional information when necessary" (McLoughlin \& Lewis, 2008, p. 136). Interviews can also be utilized as a means of gathering further information about the student from teachers, parents, and other professionals (McLoughlin \& Lewis, 2008).

When interviewing children, Kyronlampi-Kylmanen and Maatta (2011) suggested that interviews be as nonthreatening as possible, with students having opportunities to personalize files, make illustrations, or talk while engaged in play. Although this particular approach is certainly intended for younger children, some of the principles described could make the interview process less intimidating, and may offer multi-sensory components appropriate to individuals with learning disabilities.

Duvall (2006) specifically included oral interviews as an appropriate form of alternative assessment for students with specific learning disabilities enrolled in foreign language courses. With regard to second language assessment, Pinter (2011) echoed the practice suggested by Kyronlampi-Kylmanen and Maatta (2011) which involved embedding interviews within larger, more familiar activities. Ehrman (1996) emphasized that interviews also serve as a means of testing, or perhaps elaborating on, perceptions and observations of students formed by teachers. Appropriate to multisensory instruction and assessment, Pinter (2007) explored the process of integrating video and still photos of student performance into the interview, as not only a way to spur recall, but also to create context and trigger feelings and opinions. Because of the importance of a multi-sensory approach to teaching skills and concepts in a new language, which involves neurological phenomena like working memory and attention, interviewing approaches like those described by Pinter (2007) and Kyronlampi-Kylmanen and Maatta (2011) may represent an integration of instruction and assessment. 
This example is specific to teaching Spanish, namely verbs which follow regular or consistent conjugation patterns. In Spanish, regular verbs for which the infinitive form ends with "AR" are conjugated by removing the "AR" and replacing it with a different ending which corresponds to the subject pronoun. This process can be challenging, especially for native speakers of languages like English, where an analogous conjugation pattern doesn't exist. For beginning students of Spanish, it takes hours of practice and repetitions to master the conjugation of "AR" verbs. Not surprisingly, students can become frustrated with rote drills or charts; some students with SLDs are especially susceptible to being left behind in this process.

A recommended alternative is to have students create a set of cards in three categories: the verb stem (infinitive without the "AR"); the subject pronouns; the endings corresponding to subject pronouns. The subject pronouns and corresponding endings should be color-coded (red for "yo" and "o," blue for "nosotros" and "amos," etc.). This colorbased system allows the student to practice independently, with the color-coding serving as a self-correcting means of automatic feedback.

Both individual and pair practice are options with these color-coded cards, and both can meet an accepted goal of formative assessment, which is to provide students with feedback and a sense of their own mastery. With Spanish regular "AR" verb conjugation, a desired outcome is that students practice to the point of gaining automaticity. This means that not only does the conjugation process need to be learned, but that fluency is an essential part of mastery.

Pair practice can be regularly used as an in-class activity and also a means of gathering data for formative assessment purposes. This functions best as a timed activity where the subject pronouns are face-down in a pile and students have to choose the correct ending and say aloud the correct subject-verb combination ("nosotros hablamos"). Students work in pairs, with each having an assigned role as either the conjugator or the person who turns over the subject pronoun cards and tallies the number of correct responses. This has several benefits, the first being that it is a brief activity (5-10 minutes) which can be done daily for a week or two. Additionally, students can basically try to top their best score and can see their progress over time. Ultimately, this serves as both a practice activity and a reasonable way to assess which students may still be struggling with the fundamental conjugation process or with fluency.

\section{CONCLUSION}

Students with specific learning disabilities may still be more reluctant to enroll in foreign language courses, and the relative paucity of strategic attention to instruction and assessment to support these students has arguably played a role in what is likely an under-representation of students with SLDs in such courses. An important step is to recognize that students with SLDs tend to exhibit pronounced patterns of strengths and weaknesses that need to be assessed and understood in the context of the expectations of a foreign language curriculum. Effective educators also understand the intertwined nature of instruction and assessment, which is a particularly urgent consideration for students with SLDs.

Of course, it is imperative to understand that the multisensory instruction and assessment examples provided here have potential benefit for all students. However, students with SLDs may find success in foreign language courses extremely elusive without deliberate supports and considerations such as these. This can be considered a starting point, and an effort to fill gaps in theory and practice as concerns the inclusion of students with SLDs in foreign language courses. There is a continued need for rigorous research, much as effective assessment compels professional educators to gather frequent and valid data which can shape future directions.

\section{REFERENCES}

[1] Barr, V. (1993). Foreign language requirements and students with learning disabilities (ERIC Digest No. ED 355834 ). Washington, DC: ERIC Clearinghouse on Languages and Linguistics.

[2] Dal, M. (2008). Dyslexia and foreign language learning. In G. Reid, A. Fawcett, \& F. Manis (Eds.), SAGE handbook of dyslexia (pp. 439-454). London, GBR: Sage Publications, Inc.

[3] Dennis, D. V. (2009). "I'm not stupid": How assessment drives (in) appropriate reading instruction. Journal of Adolescent \& Adult Literacy, 53(4), 283-290.

[4] Duvall, E. D. (2006). Including students with disabilities in a foreign language class. Teaching Exceptional Children, 38(6), 4248.

[5] Ehrman, M. E. (1996). Understanding second language learning difficulties. Thousand Oaks, CA: SAGE Publications, Inc.

[6] Education Commission of the States. (2017). Individual state profile. http://ecs.force.com/mbdata/mbprofall?Rep=HS01 (accessed 13/2/2017).

[7] Fernald, G. (1988). Remedial techniques in basic school subjects. Austin, TX: PRO-ED.

[8] Ganschow, L., \& Schneider, E. (2006). Assisting students with foreign language learning difficulties in school. http://www.ldonlline.org/article/22725 (accessed 13/2/2017).

[9] Gillingham, A., \& Stillman, B. W. (1997). The Gillingham Manual: Remedial training for children with specific disability in reading, spelling, and penmanship ( $8^{\text {th }}$ Ed.). Cambridge, MA: Educators Publishing Service.

[10] Heward W.L, Gardner R, III, Cavanaugh R.A, Courson F.H, Grossi T.A, Barbetta P.M. (1996). Everyone participates in this class: Using response cards to increase active student response. Teaching Exceptional Children, 28, 4-11.

[11] Ketabi, S., \& Ketabi, S. (2014). Classroom and formative assessment in second/foreign language assessment and learning. Theory and Practice in Language Studies, 4(2), 435-440. 
[12] Kleinert, H. L., Cloyd, E., Rego, M., \& Gibson, J. (2007). Students with disabilities: Yes, foreign language is important. Teaching Exceptional Children, 39(3), 24-29.

[13] Koretz, D. (2008). Measuring up: What educational testing really tells us. Cambridge, MA: Harvard University Press.

[14] Kormos, J., \& Safar, A. (2008). Phonological short-term memory, working memory and foreign language performance in intensive language learning. Bilingualism: Language and Cognition, 11(2), 261-271.

[15] Kyronlampi-Kylmanen, T., \& Maatta, K. (2011). Using children as research subjects: How to interview a child aged 5 to 7 years. Educational Research and Reviews, 6(1), 87-93.

[16] Levine, M. (1987). Developmental variation and learning disorders. Cambridge, MA: Educators Publishing Service.

[17] McLoughlin, J. A., \& Lewis, R. B. (2008). Assessing students with special needs ( $7^{\text {th }}$ Ed.). Upper Saddle River, NJ: Pearson.

[18] Mayer, R. E. (2002). The promise of multimedia learning: Using the same instructional design methods across different media. Learning and Instruction, 13, 125-139.

[19] Medina, J. (2008). Brain rules: 12 principles for surviving and thriving at work, home, and school. Seattle, WA: Pear Press.

[20] Moreno, R., \& Mayer, R. E. (2007). Interactive multimodal learning environments. Educational Psychology Review, 19, 309326.

[21] Morin, A. (2017). Multi-sensory instruction: What you need to know. https://www.understood.org/en/schoollearning/partnering-with-childs-school/instructional-strategies/multisensory-instruction-what-you-need-to-know (accessed 13/2/2017).

[22] Munro, D. W., and Stephenson, J. (2009). The effects of response cards on student and teacher behavior during vocabulary instruction. Journal of Applied Behavior Analysis, 42(4), 795-800.

[23] Nikolov, M., \& Djigunović, J. M. (2006). Recent research on age, second language acquisition, and early foreign language learning. Annual Review of Applied Linguistics, 26, 234-260.

[24] Pellet, S. H. (2012). Wikis for building content knowledge in the foreign language classroom. CALICO Journal, 29(2), 224-248.

[25] Pinter, A. (2007). Benefits of peer-to-peer interaction: 10-year-old children practising with a communication task. Language Teaching Research, 11(2), 1-19.

[26] Plickers (2017). https://www.plickers.com (accessed 13/2/2017).

[27] Rhodes, N.C., \& Pufahl, I. (2009). Foreign language teaching in U.S. schools: Results of a national survey. Washington, D.C.: Center for Applied Linguistics

[28] Salend, S. J. (1998). Using portfolios to assess student performance. Teaching Exceptional Children, 31(2), 36-43.

[29] Schultz E. K., Simpson C. G., Lynch S. (2012). Specific learning disability identification: What constitutes a pattern of strengths and weaknesses? Learning Disabilities: A Multidisciplinary Journal, 18, 87-97.

[30] Scott, S. S., \& Manglitz, E. (1997). Foreign language and learning disabilities. http://www.ldonline.org/article/6606 (accessed 13/2/2017)

[31] Sparks, R. L., Artzer, M., Patton, J., Ganschow, L., Miller, K., Hordubay, D. J., \& Walsh, G. (1998). Benefits of multisensory language instruction for at-risk foreign language learners: A comparison study of high school Spanish students. Annals of Dyslexia, 48, 239-270.

[32] Sparks, R., \& Ganschow, L. (1993). The effects of multisensory structured language instruction on native language and foreign language aptitude skills of at-risk high school foreign language learners: A replication and follow-up study. Annals of Dyslexia, 43(1), 194-216.

[33] Tolbert, J. B., Killu, K., \& Lazarus, B. D. (2015). A framework for supporting students with learning disabilities in Spanish courses: Connecting learning characteristics and instructional methods. Theory and Practice in Language Studies, 5(2), 225234.

[34] Thurston, A., Duran, D., Cunningham, E., Blanch, S., \& Topping, K. (2009). International on-line reciprocal peer tutoring to promote modern language development in primary schools. Computers \& Education, 53, 462-472.

[35] Valas, H. (2001). Learned helplessness and psychological adjustment: Effects of learning disabilities and low achievement. Scandinavian Journal of Educational Research, 45(2), 101-114.

[36] Yu-Ju, C., Wu, C., \& Heng-Yu, K. (2005). The introduction of electronic portfolios to teach and assess English as a foreign language in Taiwan. TechTrends, 49 (1), 30-35.

Joshua B. L. Tolbert is an Assistant Professor of Special Education at Indiana University East. He earned a B.A. from Western Michigan University, with a double major in Spanish and art education. He later earned an M.A. in liberal studies and an Ed.D. in special education, both from the University of Michigan-Dearborn. His K-12 experience included serving as a teacher of students with learning disabilities, a well as being an instructor of Spanish and visual arts. In both research and practice, Dr. Tolbert is exploring effective strategies for teaching vocabulary to students with disabilities, with particular emphasis on learning a language beyond English. 